\title{
Influence of Low Dosage Green Extracts on CO2 Hydrate Formation
}

\author{
Sai Kiran $\mathrm{B}^{1,2}$, Rama Rao $\mathrm{G}^{2}$ and Prasad PSR ${ }^{1,2 *}$ \\ ${ }^{1}$ Academy of Scientific and Innovative Research (AcSIR), Ghaziabad, 201002, India \\ ${ }^{2}$ Gas Hydrate Division, CSIR-National Geophysical Research Institute (CSIR-NGRI), Hyderabad, \\ 500007, India
}

*Corresponding author: Pinnelli S R Prasad, Gas Hydrate Division, CSIR-National Geophysical Research Institute (CSIR-NGRI), Hyderabad-500 007, India, Tel: +91 402701 2710; Email: psrprasad@ngri.res.in

\section{Research Article \\ Volume 4 Issue 5}

Received Date: August 07, 2020

Published Date: September 15, 2020

DOI: $10.23880 /$ ppej-16000234

\section{Abstract}

Gas clathrates or the gas hydrates are the solid ice particles encapsulating gas molecules (commonly methane $-\mathrm{CH}_{4}$ and carbon dioxide $-\mathrm{CO}_{2}$ ) within the water cavities, at moderately high-pressure and low-temperature conditions. The petroleum extraction process from the deep-sea environment favours the occurrence of hydrates, and $\mathrm{CO}_{2}$ hydrates require milder p, T conditions than $\mathrm{CH}_{4}$ hydrates. Thus, chocking the pipeline network and obstructing the petroleum flow; leading to a substantial economic loss and hazardous. Conventional hydrate inhibitors (methanol, ethanol, glycols, Amino acids, and ionic liquids, etc.) are used, which are chemically toxic, costly, and required in large volumes (30-50 wt \%). Therefore a suitable additive preventing plug formation is on high demand. The present study disclosures the use of three green leaf extracts Azadirachta indica (Neem - NL), Piper betel (betel - BL), and Nelumbo nucifera (Indian lotus - LL) in low dosage (0.5 wt \%) on the $\mathrm{CO}_{2}$ hydrate formation. Experiments are conducted in the isochoric method, with $0.5 \mathrm{wt} \%$ green-additives. The hydrates nucleate at higher subcooling ( 7-9 K), and the conversion is about 33-40\%. The induction time is nearly the same both pure$\mathrm{H}_{2} \mathrm{O}$ and $\mathrm{H} 2 \mathrm{O}$ with LL, whereas, it is 3 and 4 times higher for NL and BL. The hydrate growth kinetics also indicate significant retardation ( $2-4$ times). Thus, these bio-additives, in low-dosage, could be an effective THI and also KHI for preventing the $\mathrm{CO}_{2}$ hydrates plugs.

Keywords: $\mathrm{CO}_{2}$ hydrates; Flow assurance; Low dosage; THI; KHI; Bio-additives

\section{Introduction}

Gas hydrate is the ice-like solid, transformed from liquid water and gas at some suitable temperature and pressure conditions. The hydrogen bonding forms various polyhedral cavities where the gas molecules occupy these cavities and confine their motion with the week van der wall interactions. Depending upon the guest molecule, the hydrate structure is classified into three types, namely Structure-I (sI), StructureII (sII), and Structure-H (sH). The guest molecule to cavity size ratio governs the formation pressure-temperature conditions [1]. Natural gas hydrates are the accumulation of vast gas reserves, mainly occurring in the ocean bottom sediments and permafrost regions [2-3]. They are identified in various locations across the globe [4-10]. The amount of energy estimated form these hydrate deposits is double comparative to all the other types of hydrocarbon sources. The gas hydrate occurrence was first proposed by Sir Humphrey Davy in 1810 [1]. Later with due course of time in 1934 it is established as an important topic due to blocking of pipelines in the hydrocarbon industry [11]. 


\section{Petroleum \& Petrochemical Engineering Journal}

The blocking/chocking of the gas transmission pipelines have paved a path for the new study area in the hydrocarbon industry traditionally developed has "Flow Assurance". The oil and gas industries expend millions of dollars annually to restrict the hydrate occurrence in flow loops [12]. Blocking of the pipelines not only effects the gas production but also a factor of safety concern leading to hazardous havoc $[1,13]$. Among the three hydrate structures, sI and sII are ascertained in oil and gas production, and processing [14]. Methane is the principal constituent of the Natural gas. Several studies have been proposed and developed for the methane hydrate inhibition [15-19]. But very few studies have been evolved for the $\mathrm{CO}_{2}$ hydrate inhibition. Carbon dioxide, non-hydrocarbon gas found in petroleum, and in the rare scenario in the giant pre-salt reservoirs in Brazil. The $\mathrm{CO}_{2}$ fraction could make up to $80 \%$ of the produced gas [20].

The occurrence of $\mathrm{CO}_{2}$ hydrates is high during petroleum production or $\mathrm{CO}_{2}$ re-injection in the same reservoir. The consideration of the $\mathrm{CO}_{2}$ hydrates is essential as they constitute the natural gas composition and are injected into aquifers through pipelines for $\mathrm{CO}_{2}$ sequestration [21]. Also, there are some natural gas reservoirs where the $\mathrm{CO}_{2}$ gas content is high. They are preferentially located in the South China Sea, Australian Cooper- Eromanga basin, Gulf of Thailand, the North Sea South Viking Graben, and Taranaki basin, New Zealand [22]. Thailand and Indonesia countries have gas reservoirs that have over a 0.50 -mole fraction of $\mathrm{CO}_{2}$ $[22,23]$. Therefore, the study and technology development for $\mathrm{CO}_{2}$ hydrates inhibition is a point of concern for successful offshore operation in such locations and also for the liquid $\mathrm{CO}_{2}$ transportation in pipelines.

The conventional methods adopted for the inhibition of Carbon dioxide hydrates are the use of inhibitors. These inhibitors are classified as Thermodynamic inhibitors (THI) (shifts the phase equilibrium curve to lower temperature and higher pressure, example methanol [24], ethanol [25], ethylene glycol [26], diethylene glycol [27], triethylene glycol [28], and glycerol [29].) and kinetic inhibitors (KHI) (kinetically retards the hydrate growth process and slow down the reaction process they do not change the hydrate equilibrium conditions, examples polymers, antifreeze proteins, ionic liquids, amino acids [30]). However, the bottlenecks associated with these conventional THI are expensive and required in high quantities (30-50 wt \%). With KHI, the inhibition influences is probabilistic and works below par at higher subcooling conditions and are expensive. In recent times several researchers intensively studied and proposed various amino acids as prominent THI and KHI for the carbon dioxide hydrates. Depending on several factors, the $\mathrm{CO}_{2}$ hydrate inhibition is reported [20-22, 31-35].

There is an increasing demand for hydrate inhibitors in petroleum exploitation and transportation (pipeline network) from the deep waters because the hydrates could form plugs. This problem is critical for $\mathrm{CO}_{2}$ rich gas fields, as $\mathrm{p}, \mathrm{T}$ conditions required for $\mathrm{CO}_{2}$-hydrates are mild. Present investigations explore the formation conditions of the $\mathrm{CO}_{2}-$ hydrates, using low dosage ( $0.5 \mathrm{wt} \%)$ green leaf extracts, namely, Azadirachta indica (Neem), Piper betel (betel), and Nelumbo nucifera (Indian lotus). These low dosage green extracts have various constituents that act as THI and also retards the hydrate growth kinetics leading dual role to act as KHI. Since these extracts are prepared from the powders of dried leaves, which are available in all seasons and easily soluble in water and also environmentally friendly and most important cost-effective they can be used as $\mathrm{CO}_{2}$ hydrate inhibitors comparative to the expensive and toxic conventional additives.

\section{Experimental Procedure}

\section{Materials}

$99.95 \%$ purity carbon dioxide gas is used to perform experiments procured from Bhuruka Gas Company. Deionized water type 1 is used to make the sample solution. The sample leaves were dried at ambient temperature for several days, and the dried leaves are powered in a domestic mixer (Philips- HL1643) and were sieved using a BSS-60 sieve. The sample powder $0.5 \mathrm{wt} \%$ is added to the required amount of water and stirred for 30 minutes using a magnetic spinner. The homogeneous mixed solution is filtered with Whatman filter paper. The refined and filtered solution is used as a reactant.

\section{Apparatus}

The apparatus includes a high-pressure reactor vessel ( $400 \mathrm{~mL}$ volume) made of SS-316 which consists of stirrer headward to agitate the sample solution and can hold up the pressure up to $10 \mathrm{MPa}$. The temperature control is by a closed-loop chiller (CLASSIC-AL-RCC-90) using glycol and water mixture in the selected ratio as a coolant. The temperature and pressure measurements were measured using Platinum resistance thermometers (Pt100), and a pressure transducer (WIKA, type A-10 for pressure range 0 -25 MPa with $\pm 0.5 \%$ accuracy). The stirrer rotations are controlled by a motor speed controller which operates in the range from 0-1300 rpm.

\section{Procedure}

The experiments are performed in a batch reactor following the isochoric method procedure. The filtered aqueous sample solution $89 \mathrm{~g}$ is poured into the reactor vessel. The experiments are performed in dynamic conditions. It is challenging and gruelling to structure the 


\section{Petroleum \& Petrochemical Engineering Journal}

pipeline model in the laboratory environment; instead, the tests in a stirred reactor vessel could help us understand the additives effect on the $\mathrm{CO}_{2}$ system [36]. We conducted $\mathrm{CO}_{2}$ hydrate formations with different stirring speeds in the range of 0 to 1000 rotations per minute (rpm). The stirrer headward is placed on the vessel and are clamped tightly together with the help of adjustable screws. $\mathrm{CO}_{2}$ gas with desired pressure is filled into the reactor vessel through the inlet valve using the Teledyne ISCO syringe pump. Before introducing the gas, the reactor cell is purged with sample gas for 3-4 times. The pump is disconnected after introducing the gas. The coolant circulations pipes are connected to the reactor vessel. The chiller is set to the desired experimental value to increase or decrease the temperature in the reactor vessel. The stirred head with required rpm is set into action with the help of an adjustable motor speed controller. The $\mathrm{CO}_{2}$ hydrate formation is inferred from the temperature spike because of the exothermic heat release during the hydrate crystal growth. The gas consumed in the hydrate conversion process is calculated from the observed pressure drop. The subcooling is defined as the difference between the phase equilibrium temperature at the operating pressure and the experimental formation temperature.
The hydrate dissociation is performed at slower rates to avoid the measurable deviation from the phase boundary line. Each experiment was repeated three times to obtain an average value. The schematic experimental operation is shown in Figure 1. The temperature and pressure data points are recorded every 30 seconds. In all the cycles, the experimental parameters were kept constant. The following equation defines the molar gas concentration of $\mathrm{CO}_{2}$ gas in the solidified hydrate phase during an experiment at any given time $\mathrm{t}$

$$
\Delta n H, t=n g, 0-\mathrm{ng}, \mathrm{t}=\left[\frac{P_{0} V}{Z_{O} R T_{o}}\right]-\left[\frac{P_{t} V}{Z_{t} R T_{t}}\right]
$$

Where

$\mathrm{Z}$ - is the compressibility factor, calculated using the PengRobinson equation of state.

P - Pressure, V - Volume, T - Temperature, R - Gas constant 0 - initial point, $\mathrm{t}$ - a point at any given time

The volume changes during phase transformation are neglected, and volume is considered to be constant throughout the experiment.

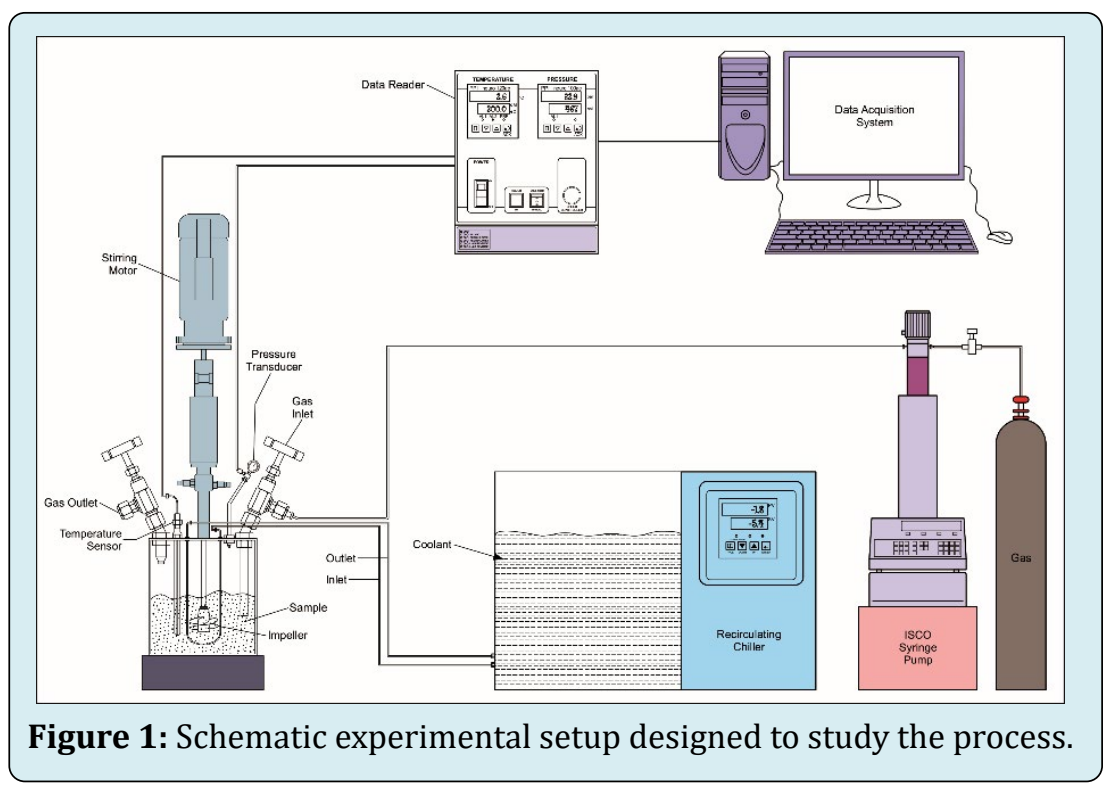

\section{Results and Discussion}

To understand the effect of bio leaf extracts on the $\mathrm{CO}_{2}$ hydrate formation, a sequence of experiments was performed. The primary objective is to assess the $\mathrm{CO}_{2}$ hydrate formation conditions using the bio-additives in the stirred configuration by varying stirring speeds $0,300,500$, and 1000 . The initial conditions for all the experiments are at $3.5 \mathrm{MPa} \mathrm{CO}$ pressure and ambient $(298 \mathrm{~K})$ temperature. In the preliminary step, the tests have been performed using all three sample solutions (BL, NL, and LL) without any agitation (0 rpm) and pure $\mathrm{H}_{2} \mathrm{O}$ (bulk) is presented as the control experiment. The above said pressure-temperature cycles had been reported in our earlier work [37]. With 0 rpm arrangement, lesser hydrate conversion (8-12\%) and higher subcooling (10-13 K) and greater induction time $(-2-6$ hours) are observed with these green additives. The above said result provokes to use these bio-additives as suitable inhibitors for the $\mathrm{CO}_{2}$ hydrate formation. Since to scale these powders as efficient inhibitors and use them in realtime applications, the experiments need to be performed in the dynamic conditions. The agitation has been performed 


\section{Petroleum \& Petrochemical Engineering Journal}

using a speed control motor with 300, 500, and $1000 \mathrm{rpm}$. In Figure 2, the temperature-pressure trajectories for the $\mathrm{CO}_{2}$

hydrate formation using BL, NL, LL, and bulk $\mathrm{H}_{2} \mathrm{O}$ for 500 rpm are shown.

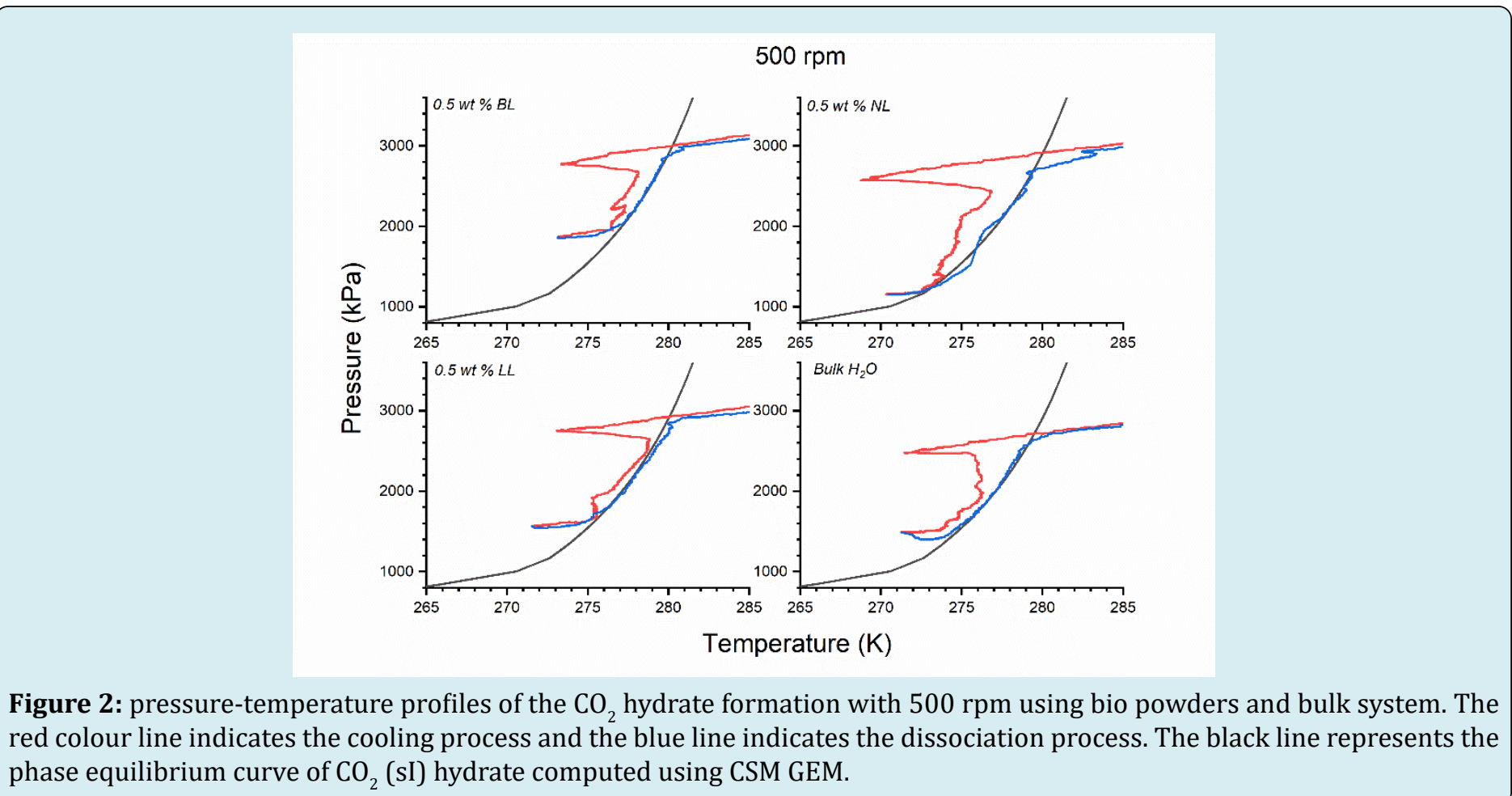

Form the figure 2, it is evident that the addition of these bio-extracts is not altering the phase equilibrium conditions of the $\mathrm{CO}_{2}$ hydrate. In all the agitations pure $\mathrm{H}_{2} \mathrm{O}-\mathrm{CO}_{2}$ system is performed as the control experiment. The red colour line indicates the cooling process and the blue line indicates the dissociation process. The black line represents the phase equilibrium curve of $\mathrm{CO}_{2}$ (sI) hydrate computed using CSM GEM [1]. The above figure shows the amount of subcooling required in triggering the hydrate formation with the rotation speed of $500 \mathrm{rpm}$ is nearly 7, 10, 8 and $6 \mathrm{~K}$ for BL, NL, LL and pure system respectively. BL and LL require the almost same amount of subcooling, whereas, NL required an additional $2 \mathrm{~K}$ showing the highest inhibition $(10 \mathrm{~K})$. The subcooling is defined as the difference between the phase equilibrium temperature at the operating pressure and the experimental formation temperature. The pressure-temperature plots for the other two rpms (300 and 1000) are similar to $500 \mathrm{rpm}$, and the dissociation pattern follows the hydrate equilibrium curve. The critical parameters for evaluating materials, as hydrate inhibitors, are subcooling $(\Delta \mathrm{T})$, induction time (min), percentage of hydrate conversion ( $\% \mathrm{H}_{2} \mathrm{O}$ conversion) and the amount of time taken for the hydrate growth $\left(\mathrm{t}_{90}\right.$ kinetics) ( $\mathrm{t}_{90}$ is the amount of time taken for the $90 \%$ of the hydrate conversion). We systematically measured all these for chosen green additives for $\mathrm{CO}_{2}$-hydrates. Histograms in Figure 3 show the amount of subcooling required in the presence of the three natural bio powders and bulk system with different rotations speed. The bio powders require higher subcooling comparatively than the pure system. Since at $0 \mathrm{rpm}$ the system is under the static condition the amount of subcooling required is very high $14.6 \pm 0.7,12 \pm 0.2,10 \pm$ 2 and $10.3 \pm 1.4$ for BL, NL, LL, and bulk system respectively. The average degree of subcooling for the $\mathrm{CO}_{2}$ hydrates in the dynamic state is in the order (high to low) is $\mathrm{NL}>\mathrm{LL}>\mathrm{BL}>\mathrm{Bulk}$ system with inhibition capacity of $9.1 \pm 0.7,7.9 \pm 0.06,6.8 \pm$ 0.4 and $6.3 \pm 0.5 \mathrm{~K}$ respectively.

The bio extracts with the NL shows the highest subcooling for triggering $\mathrm{CO}_{2}$-hydrates. With increasing rpm, the hydrate formation temperature is not influenced and requires the same amount of subcooling. The bio extracts show functional inhibition capacity until their respective nucleation temperature. Further cooling triggers the hydrate nucleation, and the growth takes place. Thus, within the threshold temperature window, these bio extracts can work as effective THI's for the $\mathrm{CO}_{2}$ hydrates.

Another critical aspect being studied is the amount of induction time required for the $\mathrm{CO}_{2}$ hydrates to trigger, crossing the phase equilibrium curve. Figure 4 describes the influence of bio powders on the induction time for $\mathrm{CO}_{2}$ hydrates. 


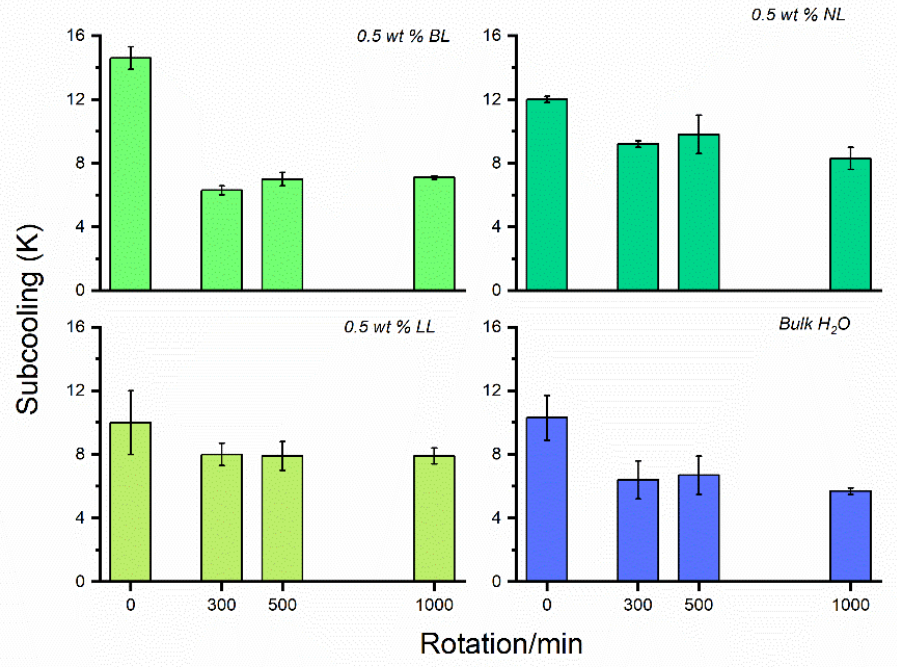

Figure 3: The histograms represent the amount of subcooling required for the $\mathrm{CO}_{2}$ hydrate formation with $\mathrm{BL}, \mathrm{NL}, \mathrm{LL}$, and bulk system at different rpm's.

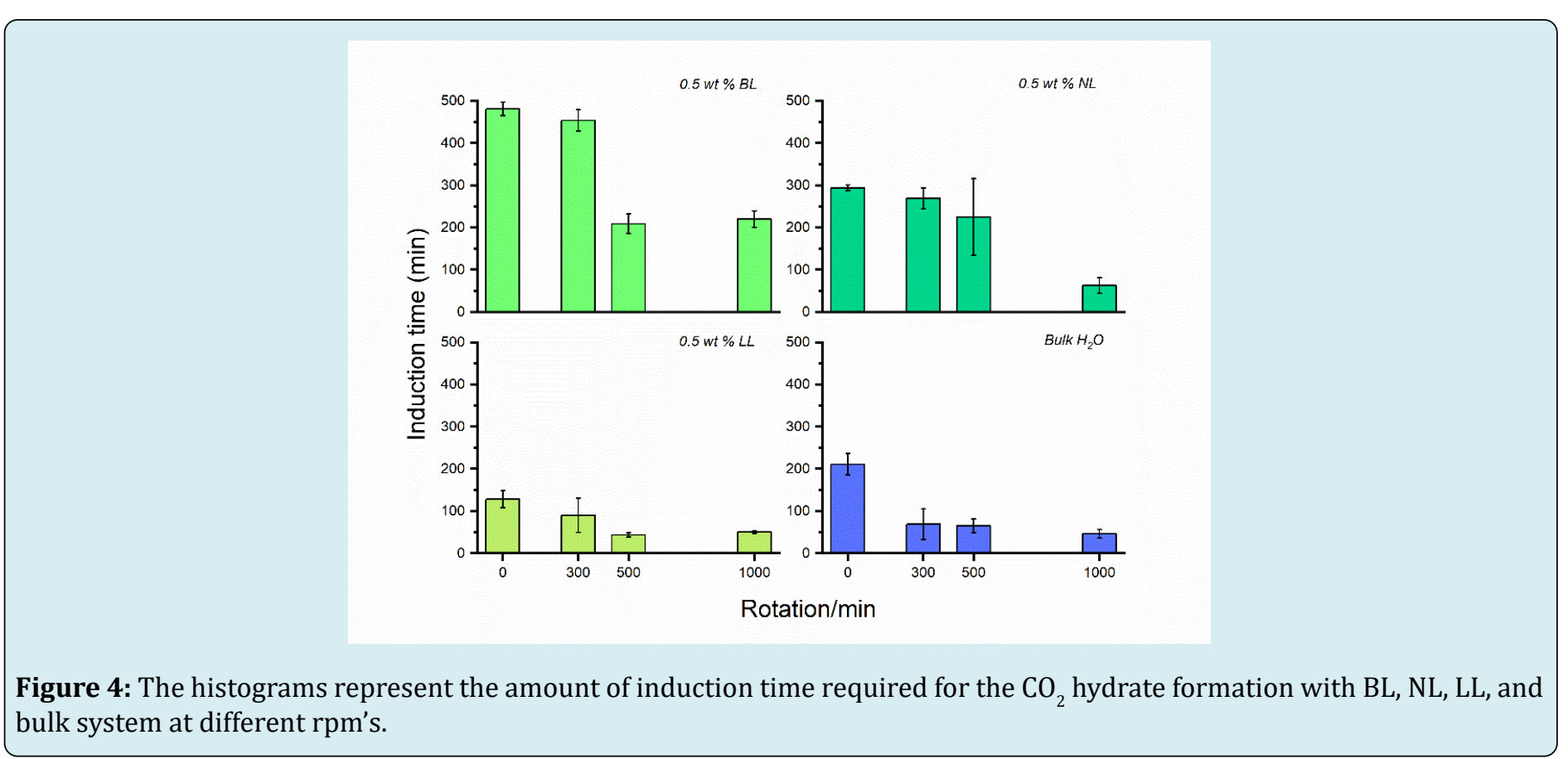

Under steady-state or $0 \mathrm{rpm}$ the amount of time required for the hydrate to nucleate is in the order (high to low) $\mathrm{BL}>\mathrm{NL}>$ Bulk>LL with 481 $\pm 16,294 \pm 7,211 \pm 25,128 \pm$ 20 minutes respectively. From the graph, it is clear that in the bulk system with increasing rotations, the induction time is decreased. Since the stirring enhance the interfacial mass transport, thereby quickening the hydrate growth [3840]. In the LL context, it shows poor behaviour on induction time, and also with increasing rotations, the induction time is decreased behaving similarly like the bulk system. In the NL the induction time is high ( $250 \mathrm{~min})$ up to threshold of $500 \mathrm{rpm}$ and upon on reaching $1000 \mathrm{rpm}$ the induction time is lowered by four times compared to 300 and 500 rpms. BL shows the higher induction time up to a threshold of 300 rpm, and upon crossing the threshold, it is lowered by two times. In the dynamic state, the degree of induction time form (high to low) is BL> NL> LL> Bulk system, respectively. 


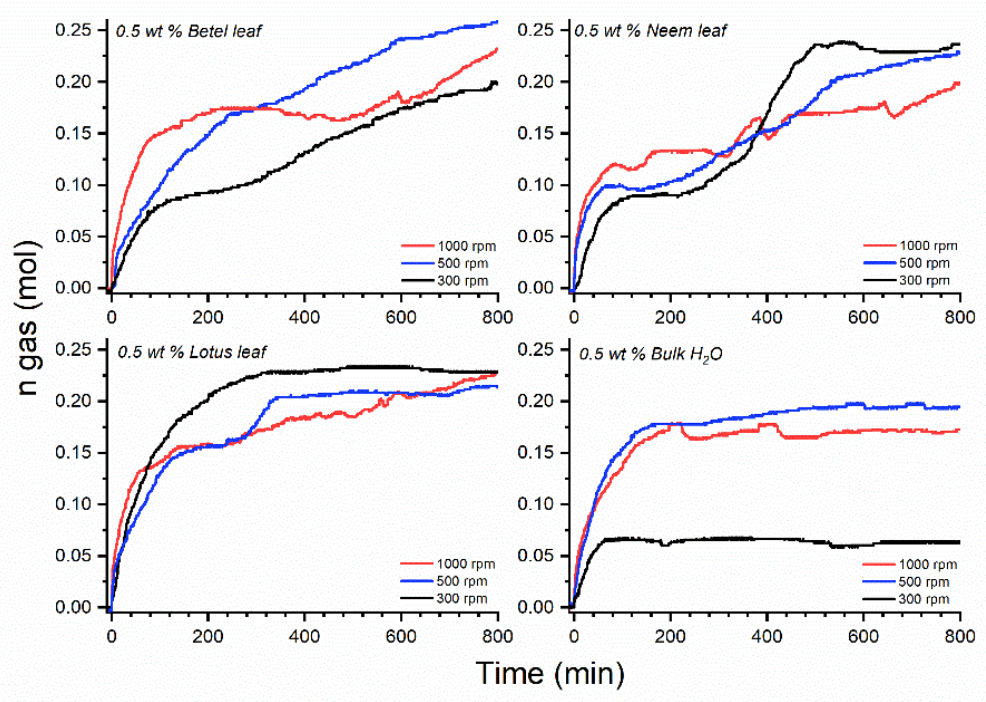

Figure 5: Plot represents the time vs gas consumed during the hydrate formation. The red colour line indicates for 1000 , the blue colour line indicates for 500, and the black colour line indicates for 300 rpm respectively.

In Figure 5, the formation kinetics of the three bioadditives compared with the bulk system is shown. The black, blue, and red colour indicate the gas uptake kinetics for 300 , 500 , and 1000 rpms respectively. The gas uptake kinetics in the presence of low dosage bio powders is shown up to 800 minutes. The first 40 minutes of the hydrate growth is rapid, and later with an increase in time, the growth is slowed. The $t_{90}$ kinetics is higher for the NL and then BL and LL and lastly bulk system. The addition of these bio extracts delays the hydrate growth and acts as effective KHI's for the $\mathrm{CO}_{2}$ hydrate system. The average time for growth kinetics using the bio powders with increasing rotations requires more considerable time. Systematically measured parameters were tabulated in Table 1.

The overall gas uptake or the amount of hydrate conversion using bio powders in stirring mode is nearly $33-40 \%$ whereas the bulk system is about $27 \%$. Figure 6 shows the hydrate yield for all the bio powders compared with bulk water. The amount of hydrate yield is very less in static conditions since the constituents in the bio extracts profoundly hinder the $\mathrm{CO}_{2}$ hydrate growth. The overall hydrate conversion is less than $50 \%$ in the presence of bio extracts. The reason for the lesser conversion is still obscure but can be a useful material to retard the carbon dioxide hydrates.

The exact reason for the inhibitory function of these bio extracts is not clearly understood. It requires further detailed investigations. On the other hand, Elechi, et al. [41] reported the inhibitory effect of a medicinal plant extract named Costaceae, which contains a wide variety of bioactive compounds like phenols, alkaloid, flavonoid, tannins, and saponins. These compounds could be responsible for assisting the hydrate formation to lower temperatures [41]. Similarly, all the three bio-additives constitute of several bioactive compounds. The neem leaf extracts may contain triterpenoids, alkaloids, phenolic compounds, flavonoids, carotenoids, ketones, and steroids. The most biologically active compound is azadirachtin. The phytochemistry screening of Neem leaves extracts revealed the presence of tannins, saponins, flavonoids, alkaloids, glycosides, reducing sugars, polyphenols [39]. The betel leaf named piper betel belongs to the Piperaceae family. Betel leaves contain reasonable amounts of vitamins, particularly nicotinic acid, ascorbic acid, and carotin. They also comprise all essential amino acids except glycine, histidine, and arginine. Large concentrations of asparagines are present while glycine and proline occur in a reasonable amount [42]. The lotus leaf possesses pharmacologic and physiologic compounds, which including hepatoprotective, antioxidant, antidiarrheal, antiviral, immunomodulatory, and antiobesity effects. The leaves also contain several flavonoids and alkaloids [43]. All three classes of leaves possess several bio-active components which mostly consist of proteins, antioxidants. Close observations give an idea that these antioxidants which inhibit the reactions promoted by oxygen compounds could be responsible for the hydrate nucleation to occur at lower temperatures and retards the $\mathrm{CO}_{2}$ hydrate growth. A detailed study is required in understanding the micro-level analysis 


\section{Petroleum \& Petrochemical Engineering Journal}

of these components. At present, the study exposes the use of natural bio powders in low concentration ( 0.5 wt \%) can act as effective thermodynamic inhibitors and also KHI for the $\mathrm{CO}_{2}$ hydrates. These components are marked to be very useful than traditional inhibitors like glycol or methanol.

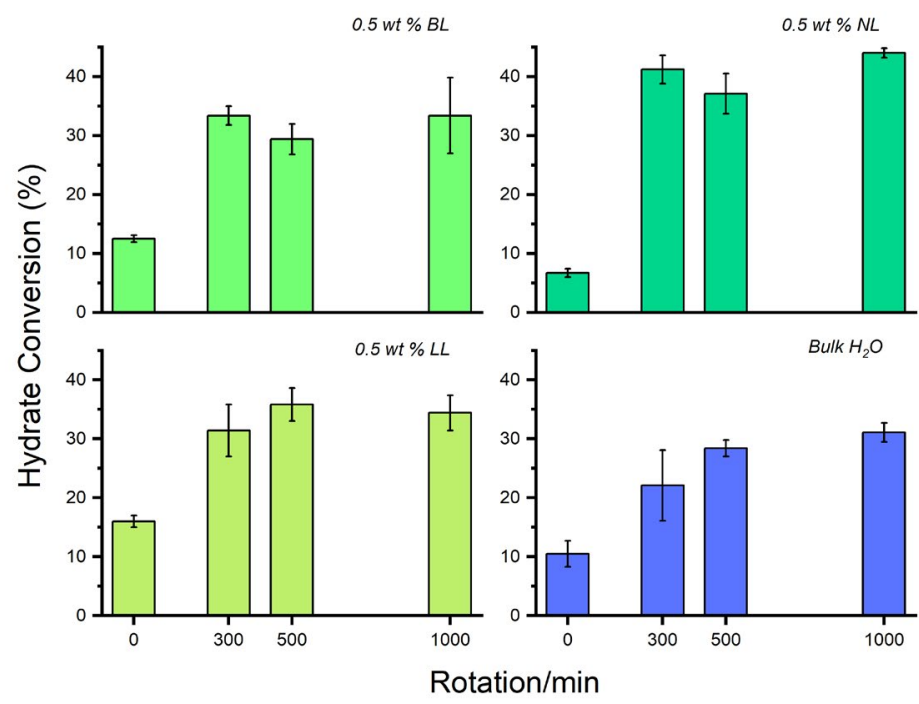

Figure 6: The histograms represent the amount of hydrate conversion occurred in the process with various rpms.

\begin{tabular}{|c|c|c|c|c|}
\hline Rotation/minute & $\% \mathrm{H}_{2} \mathrm{O}$ conversion & Induction time (min) & Subcooling $\Delta \mathrm{T}(\mathrm{K})$ & $t_{90}$ Kinetics (min) \\
\hline \multicolumn{5}{|c|}{ Bulk $\mathrm{H}_{2} \mathrm{O}$} \\
\hline 0 & $10.5 \pm 2.2$ & $211 \pm 25$ & $10.3 \pm 1.4$ & $362 \pm 58$ \\
\hline 300 & $22.09 \pm 6$ & $69 \pm 36$ & $6.4 \pm 1.2$ & $61 \pm 10$ \\
\hline 500 & $28.4 \pm 1.4$ & $65.2 \pm 16.3$ & $6.7 \pm 1.2$ & $196 \pm 79$ \\
\hline 1000 & $31.1 \pm 1.6$ & $46.1 \pm 10.2$ & $5.7 \pm 0.2$ & $116 \pm 3$ \\
\hline \multicolumn{5}{|c|}{ Lotus Leaf Extract } \\
\hline 0 & $16 \pm 1$ & $128 \pm 20$ & $10 \pm 2$ & $538 \pm 40$ \\
\hline 300 & $31.4 \pm 4.4$ & $90.25 \pm 40.6$ & $8 \pm 0.7$ & $205 \pm 30$ \\
\hline 500 & $35.8 \pm 2.8$ & $43.5 \pm 4.9$ & $7.9 \pm 0.9$ & $296 \pm 80$ \\
\hline 1000 & $34.4 \pm 3$ & $50.2 \pm 2.7$ & $7.9 \pm 0.5$ & $241 \pm 43$ \\
\hline \multicolumn{5}{|c|}{ Betel Leaf Extract } \\
\hline 0 & $12.5 \pm 0.6$ & $481 \pm 16$ & $14.6 \pm 0.7$ & $161 \pm 14$ \\
\hline 300 & $33.4 \pm 1.6$ & $454 \pm 25$ & $6.3 \pm 0.28$ & $120 \pm 55$ \\
\hline 500 & $29.4 \pm 2.6$ & $209 \pm 23$ & $7 \pm 0.42$ & $469 \pm 43$ \\
\hline 1000 & $33.4 \pm 6.4$ & $220 \pm 19.4$ & $7.1 \pm 0.1$ & $364 \pm 34$ \\
\hline \multicolumn{5}{|c|}{ Neem Leaf Extract } \\
\hline 0 & $6.7 \pm 0.7$ & $294 \pm 7$ & $12 \pm 0.2$ & $683 \pm 42$ \\
\hline 300 & $41.2 \pm 2.4$ & $269 \pm 25$ & $9.2 \pm 0.2$ & $398 \pm 0.7$ \\
\hline 500 & $37.1 \pm 3.43$ & $225 \pm 91$ & $9.8 \pm 1.2$ & $490 \pm 4.9$ \\
\hline 1000 & $44 \pm 0.8$ & $62.6 \pm 18.3$ & $8.3 \pm 0.7$ & $706 \pm 19$ \\
\hline
\end{tabular}

Table 1: The average values of measured parameters such as total hydrate yield, subcooling, induction time, and $t_{90}$ kinetics during the hydrate formation. 


\section{Petroleum \& Petrochemical Engineering Journal}

\section{Conclusions}

In summary, we investigated the $\mathrm{CO}_{2}$-hydrate formation behaviour in an aqueous solution, consisting of soluble biopowders, namely Azadirachta indica (Neem), Piper betel (betel), and Nelumbo nucifera (Indian lotus). The addition of these bio-additives in low-dosage (0.5 wt \%) demands a higher subcooling ( $\sim 7-9 \mathrm{~K})$ for the $\mathrm{CO}_{2}$ hydrates nucleation. The average induction time is relatively high in BL and NL up to their threshold rpms. LL shows inferior performance in induction time. In comparison with the bulk system, the average hydrate growth kinetics (retarding the hydrate growth) is 4.2 times higher in the NL system and 2.2 times in the LL and BL systems. The overall hydrate conversion in the presence of these bio leaf extract is less than $50 \%$. Higher subcooling, sluggish kinetics, more considerable induction time, and lesser hydrate conversion in the presence of these bio-additives for the $\mathrm{CO}_{2}$ hydrates marks these materials has effective $\mathrm{CO}_{2}$ hydrate inhibitors. Conclusively, the three naturally occurring bio-additives which are low cost, less toxic, and readily available have been assessed and identified, which has the competency to act as potential THI and KHI for the $\mathrm{CO}_{2}$ hydrates.

\section{Acknowledgement}

Authors sincerely thank the Director of the National Geophysical Research Institute, Hyderabad, for his encouragement, and permission to publish this paper (NGRI/ Lib/2020/Pub-154).

\section{References}

1. Sloan ED, Koh CA (2007) Clathrate hydrates of natural gases. $3^{\text {rd }}$ (Edn.), CRC press, UK, pp: 752.

2. Makogon YF (1965) Hydrate formation in the gasbearing beds under permafrost conditions. Gazovaia Promyshlennost 5: 14-15.

3. Yang J, Hassanpouryouzband A, Tohidi B, Chuvilin E, Bukhanov B, et al. (2019) Gas Hydrates in Permafrost: Distinctive Effect of Gas Hydrates and Ice on the Geomechanical Properties of Simulated Hydrate-Bearing Permafrost Sediments. Journal of Geophysical Research: Solid Earth 124(3): 2551-2563.

4. Boswell R, Schoderbek D, Collett TS, Ohtsuki S, White M, et al. (2016) The Ignik Sikumi Field Experiment, Alaska North Slope: Design, Operations, and Implications for CO2-CH4 Exchange in Gas Hydrate Reservoirs. Energy \& Fuels 31(1): 140-153.

5. Liang J, Zhang W, Lu J, Wei J, Kuang Z, et al. (2019) Geological occurrence and accumulation mechanism of natural gas hydrates in the eastern Qiongdongnan Basin of the South China Sea: Insights from site GMGS5-W9-2018. Marine Geology 418.

6. Jin Y, Kida M, Yoneda J, Konno Y, Oshima M, et al. (2019) Natural Gas Hydrates Recovered from the Umitaka Spur in the Joetsu Basin, Japan: Coexistence of Two Structure-I Hydrates with Distinctly Different Textures and Gas Compositions within a Massive Structure. ACS Earth and Space Chemistry 4 (1): 77-85.

7. Kraev G, Rivkina E, Vishnivetskaya T, Belonosov A, Van Huissteden J (2019) Methane in Gas Shows from Boreholes in Epigenetic Permafrost of Siberian Arctic. Geosciences 9(2): 67.

8. Manakov AY, Khlystov OM, Hachikubo A, Minami K, Yamashita S (2019) Structural Studies of Lake Baikal Natural Gas Hydrates. Journal of Structural Chemistry 60(9): 1437-1455.

9. Kumar P, Collett TS, Shukla KM, Yadav US, Lall MV (2019) India National Gas Hydrate Program Expedition-02: Operational and technical summary. Marine and Petroleum Geology 108: 3-38.

10. Hillman JIT, Burwicz E, Zander T, Bialas J, Klaucke I, et al. (2018) Investigating a gas hydrate system in apparent disequilibrium in the Danube Fan, Black Sea. Earth and Planetary Science Letters 502: 1-11.

11. Hammerschmidt EG (1934) Formation of Gas Hydrates in Natural Gas Transmission Lines. Industrial \& Engineering Chemistry 26(8): 851-855.

12. Sloan ED (2003) Fundamental principles and applications of natural gas hydrates. Nature 426: 353359.

13. Sloan ED (2005) A changing hydrate paradigm-from apprehension to avoidance to risk management. Fluid Phase Equilibria 228-229: 67-74.

14. Sloan ED (2010) Natural gas hydrates in flow assurance. Gulf Professional Publishing, pp: 224

15. Tang C, Liang D (2019) Inhibitory effects of novel green inhibitors on gas hydrate formation. Chinese Journal of Chemical Engineering 27(9): 2107-2117.

16. Semenov AP, Mendgaziev RI, Stoporev AS, Gushchina YF, Anikushin BM, et al. (2019) Synergism of Methanol and Magnesium Chloride for Thermodynamic Inhibition of Methane Hydrate. Chemistry and Technology of Fuels and Oils 54(6): 738-742.

17. Altamash T, Qureshi MF, Aparicio S, Aminnaji M, Tohidi 


\section{Petroleum \& Petrochemical Engineering Journal}

B, et al. (2017) Gas hydrates inhibition via combined biomolecules and synergistic materials at wide process conditions. Journal of Natural Gas Science and Engineering 46: 873-883.

18. Altamash T, Aparicio S, Atilhan M (2019) An experimental study on doubly salt effect for methane hydrate inhibition. Journal of Natural Gas Science and Engineering 72.

19. Cheng L, Wang L, Li Z, Liu B, Chen G (2019) Inhibition Effect of Kinetic Hydrate Inhibitors on the Growth of Methane Hydrate in Gas-Liquid Phase Separation State. Energies 12(23): 4482.

20. Da Silva Ramos A, Pires JP, Medina Ketzer JM, Espíndola de Araújo G, Lourega RV (2020) Synthesis of new CO2 hydrate inhibitors. Journal of Natural Gas Science and Engineering 75.

21. Roosta H, Dashti A, Mazloumi SH, Varaminian F (2016) Inhibition properties of new amino acids for prevention of hydrate formation in carbon dioxide-water system: Experimental and modeling investigations. Journal of Molecular Liquids 215: 656-663.

22. Bavoh CB, Partoon B, Lal B, Gonfa G, Foo Khor S, et al. (2017) Inhibition effect of amino acids on carbon dioxide hydrate. Chemical Engineering Science 171: 331-339.

23. Nasir Q, Lau KK, Lal B, Sabil KM (2014) Hydrate Dissociation Condition Measurement of CO2-Rich Mixed Gas in the Presence of Methanol/Ethylene Glycol and Mixed Methanol/Ethylene Glycol + Electrolyte Aqueous Solution. Journal of Chemical \& Engineering Data 59(11): 3920-3926.

24. Dholabhai PD, Parent JS, Bishnoi PR (1996) Carbon Dioxide Hydrate Equilibrium Conditions in Aqueous Solutions Containing Electrolytes and Methanol Using a New Apparatus. Industrial \& Engineering Chemistry Research 35(3): 819-823.

25. Mohammadi AH, Afzal W, Richon D (2008) Experimental Data and Predictions of Dissociation Conditions for Ethane and Propane Simple Hydrates in the Presence of Distilled Water and Methane, Ethane, Propane, and Carbon Dioxide Simple Hydrates in the Presence of Ethanol Aqueous Solutions. Journal of Chemical \& Engineering Data 53(1): 73-76.

26. Majumdar A, Mahmoodaghdam E, Bishnoi PR (2000) Equilibrium Hydrate Formation Conditions for Hydrogen Sulfide, Carbon Dioxide, and Ethane in Aqueous Solutions of Ethylene Glycol and Sodium Chloride. Journal of Chemical \& Engineering Data 45(1): 20-22.
27. Afzal W, Mohammadi AH, Richon D (2008) Experimental Measurements and Predictions of Dissociation Conditions for Methane, Ethane, Propane, and Carbon Dioxide Simple Hydrates in the Presence of Diethylene Glycol Aqueous Solutions. Journal of Chemical \& Engineering Data 53(3): 663-666.

28. Afzal W, Mohammadi AH, Richon D (2007) Experimental Measurements and Predictions of Dissociation Conditions for Carbon Dioxide and Methane Hydrates in the Presence of Triethylene Glycol Aqueous Solutions. Journal of Chemical \& Engineering Data 52(5): 20532055.

29. Mohammadi AH, Kraouti I, Richon D (2008) Experimental Data and Predictions of Dissociation Conditions for Methane, Ethane, Propane, and Carbon Dioxide Simple Hydrates in the Presence of Glycerol Aqueous Solutions. Industrial \& Engineering Chemistry Research 47(21): 8492-8495.

30. Kelland MAA (2018) Review of Kinetic Hydrate Inhibitors from an Environmental Perspective. Energy \& Fuels 32(12): 12001-12012.

31. Prasad PSR, Kiran BS (2018) Are the amino acids thermodynamic inhibitors or kinetic promoters for carbon dioxide hydrates? Journal of Natural Gas Science and Engineering 52: 461-466.

32. Prasad PSR, Sai Kiran B (2018) Clathrate Hydrates of Greenhouse Gases in the Presence of Natural Amino Acids: Storage, Transportation and Separation Applications. Sci Rep 8(1).

33. Prasad PSR, Kiran BS, Sain K (2018) Effectiveness of amino acids for carbon storage and utilization applications. Current Science 114(6): 1163-1165.

34. Mehrabi K, Javanmardi J, Rasoolzadeh A, Mohammadi AH (2020) Thermodynamic modeling of clathrate hydrate stability conditions in the presence of amino acid aqueous solution. Journal of Molecular Liquids 313.

35. Sa JH, Lee BR, Park DH, Han K, Chun HD, et al. (2011) Amino acids as natural inhibitors for hydrate formation in CO2 sequestration. Environ Sci Technol 45(13): 58855891.

36. Daraboina N, Linga P, Ripmeester J, Walker VK, Englezos P (2011) Natural Gas Hydrate Formation and Decomposition in the Presence of Kinetic Inhibitors. 2. Stirred Reactor Experiments. Energy \& Fuels 25(10): 4384-4391.

37. Kiran BS, Prasad PSR (2018) Storage of Methane Gas 


\section{Petroleum \& Petrochemical Engineering Journal}

in the Form of Clathrates in the Presence of Natural Bioadditives. ACS Omega 3(12): 18984-18989.

38. Skovborg P, Ng HJ, Rasmussen P, Mohn U (1993) Measurement of induction times for the formation of methane and ethane gas hydrates. Chemical Engineering Science 48(3): 445-453.

39. Parent JS, Bishnoi PR (1996) Investigations Into The Nucleation Behaviour of Methane Gas Hydrates. Chemical Engineering Communications 144(1): 51-64.

40. Ke W, Svartaas TM (2011) Effects of stirring and cooling on methane hydrate formation in a high-pressure isochoric cell. Proceedings of the 7th International Conference on Gas Hydrates, Edinburgh, Scotland, United Kingdom.
41. Elechi VU, Ikiensikimama SS, Akaranta O, Ajienka JA, Okon OE (2019) Investigation of Plant Family Costaceae Extract as Gas Hydrate Inhibitor in a Simulated Offshore Environment. International Journal of Science and Engineering Investigations 8(84): 92-102.

42. Eid A, Jaradat N, Elmarzugi N (2017) A Review of chemical constituents and traditional usage of Neem plant (Azadirachta Indica). Palestinian Medical and Pharmaceutical Journal 2(2): 75-81.

43. Huang CF, Chen YW, Yang CY, Lin HY, Way TD, et al. (2011) Extract of lotus leaf (Nelumbo nucifera) and its active constituent catechin with insulin secretagogue activity. J Agric Food Chem 59(4): 1087-1094. 